\title{
Frequency and predictors of diagnostic coronary angiography and percutaneous coronary intervention related to stroke
}

\author{
Bartłomiej Staszczak', Krzysztof P Malinowski², Wojciech Wańha³, Zbigniew Siudak4, Magdalena Jędrychowska', \\ Michał Susuł', Sławomir Surowiec', Szymon Darocha ${ }^{5}$, Andrzej Surdacki',2, Marcin Kurzyna ${ }^{5}$, Wojciech Wojakowski, \\ Jacek Legutko ${ }^{6}$, Krzysztof Bartuś', Stanisław Bartuś1,2, Rafał Januszek ${ }^{1,8}$
}

\author{
'Department of Cardiology and Cardiovascular Interventions, University Hospital, Kraków, Poland \\ ${ }^{2}$ Institute of Cardiology, Jagiellonian University Medical College, Kraków, Poland \\ ${ }^{3}$ Department of Cardiology and Structural Heart Diseases, Medical University of Silesia, Katowice, Poland \\ ${ }^{4}$ Collegium Medicum, Jan Kochanowski University, Kielce, Poland \\ ${ }^{5}$ Department of Pulmonary Circulation, Thromboembolic Diseases and Cardiology, Center of Postgraduate Medical Education, European Health Center, Otwock, Poland \\ ${ }^{6}$ Department of Interventional Cardiology, Institute of Cardiology, Jagiellonian University Medical College, John Paul II Hospital, Kraków, Poland \\ `Department of Cardiovascular Surgery and Transplantology, Jagiellonian University Medical College, John Paul II Hospital, Kraków, Poland \\ ${ }^{8}$ Department of Clinical Rehabilitation, University of Physical Education, Kraków, Poland
}

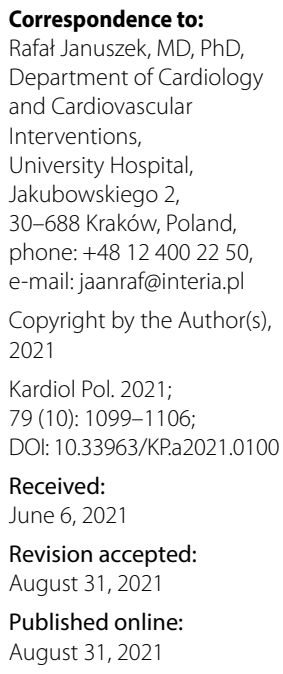

Correspondence to: Rafał Januszek, MD, PhD, Department of Cardiology and Cardiovascular Interventions, University Hospital, Jakubowskiego 2 , 30-688 Kraków, Poland, phone: +48 124002250 e-mail: jaanraf@interia.pl Copyright by the Author(s), 2021

Kardiol Pol. 2021;

79 (10): 1099-1106;

DOI: 10.33963/KP.a2021.0100

Received:

June 6, 2021

Revision accepted:

August 31, 2021

Published online:

August 31, 2021

A B S T R A C T
Background: Stroke related to percutaneous coronary interventions ( $P C l s)$ is an infrequent complication, which can be potentially life-threatening and can lead to serious disability.

Aims: This study aimed to assess the relationship between the type of coronary procedure and incidence of stroke, as well as its predictors.

Methods: This retrospective analysis was performed on prospectively collected data gathered in the Polish National Registry of Percutaneous Coronary Interventions (ORPKI) between January 2014 and December 2019 and included 1177161 coronary procedures. Among them, 650674 patients underwent isolated diagnostic coronary angiography (DCA), and $526487 \mathrm{PCl}$. Stroke was diagnosed in 157 patients $(0.013 \%)$, of which $100(0.015 \%)$ happened during DCA and $57(0.011 \%)$ during PCl. Multivariable logistic regression analysis was performed to separate predictors of stroke in patients undergoing coronary angiography and $\mathrm{PCl}$.

Results: The percentage of patients with periprocedural stroke was higher in the group treated with isolated DCA during the analyzed time. Among predictors of stroke in patients undergoing DCA, we confirmed prior stroke $(P<0.001)$, contrast amount $(P=0.007)$, femoral access $(P=0.002)$, unfractionated heparin use $(P=0.01)$, direct transport to the catheterization laboratory $(P=0.04)$, older age $(P<0.001)$ and multi-vessel disease $(P<0.001)$. While for $\mathrm{PCl} \pm \mathrm{DCA}$, these were prior stroke $(P<0.001)$, thrombolysis $(P=0.003)$, treatment with bivalirudin $(P<0.001)$, and acetylsalicylic acid loading during $\mathrm{PCl}(P=0.003)$.

Conclusions: Based on the large national registry, $\mathrm{PCl} \pm \mathrm{DCA}$ is associated with fewer risk factors and a lower rate of periprocedural strokes than isolated DCA.

Key words: coronary angiography, percutaneous coronary intervention, periprocedural complication, stroke

Kardiol Pol 2021; 79, 10: 1099-1106

\section{INTRODUCTION}

Both diagnostic coronary angiography (DCA) and percutaneous coronary interventions ( $\mathrm{PCls}$ ) are the gold standard and daily performed procedures in modern cardiology for the diagnosis and treatment of coronary artery disease. Clinical and epidemiological data have shown that one of the most severe and life-threatening complications related to high mortality is periprocedural stroke; however, modern diagnostic and therapeutic strategies make it possible to significantly reduce the adverse effects of cardiac catheterization related cerebrovascular events [1-3]. Stroke is considered the second leading cardiovascular cause of death worldwide and is a major cause of disability, as ischemic heart disease is known to be the most common. 
WHAT'S NEW?

Both diagnostic coronary angiography (DCA) and percutaneous coronary interventions (PCIs) are the gold standard for the diagnosis and treatment of coronary artery disease. This study aimed to assess the relationship between the type of coronary procedure and incidence of stroke, as well as its predictors. This analysis included 1177161 coronary procedures. We found that the incidence of periprocedural stroke did not change in patients undergoing DCA while it decreased in patients treated with $\mathrm{PCl} \pm \mathrm{DCA}$. Among the non-modifiable predictors of stroke in patients undergoing DCA (prior stroke, age, more advanced and disseminated coronary atherosclerosis, femoral access and contrast amount), we also distinguished intravascular ultrasound, optical coherence tomography, unfractionated heparin use during DC, and direct transport to the catheterization laboratory. The predictors of periprocedural stroke in patients treated with $\mathrm{PCI} \pm \mathrm{DCA}$ included, among others, those well-recognized ones, such as thrombolysis and prior stroke, treatment with bivalirudin, and acetyl-salicylic acid loading during PCI.

It affects patients undergoing isolated DCA as well as PCI. The previously available registries indicate that periprocedural stroke occurs in $0.05 \%-0.1 \%$ of DCA and $0.18 \%-0.44 \%$ of PCls [4]. However, formerly provided data may be limited [5]. The last years have shown a significant upward trend in the number of elder patients with a higher number of risk factors treated with cardiovascular procedures [6]. Other worth-mentioning factors that may have an impact on the frequency of periprocedural stroke are vascular access, clinical presentation, type of catheter, the progress of atherosclerosis, and type of procedure (thrombectomy, rotational atherectomy, etc.) [7-9]. Despite all the improvements in reperfusion strategies, such as using radial access, smaller catheters, and pharmacotherapy, achieved in the last few years, the incidence of periprocedural stroke remains the same or has even slightly increased [10].

In the present study, we aimed to assess the frequency of periprocedural stroke in patients undergoing DCA and $\mathrm{PCl} \pm \mathrm{DCA}$ to determine their predictors in comparison with other available registries.

\section{METHODS}

\section{Study design and patient population}

This retrospective analysis was performed on prospectively collected data. Data for conducting the current study were obtained from the Polish National Registry of Percutaneous Coronary Interventions (ORPKI, Ogólnopolski Rejestr Procedur Kardiologii Inwazyjnej) [11]. Data were collected between January 2014 and December 2019. We selected 1177161 patients qualified for diagnostic coronary angiography (DCA) alone or followed by $\mathrm{PCl}$ during the analyzed period. Among them, 650674 patients underwent DCA alone, and 526487 DCA underwent DCA and PCl, or $\mathrm{PCl}$ alone. There were 100 periprocedural strokes in the DCA group $(0.015 \%)$ and 57 periprocedural strokes in the $\mathrm{DCA} \pm \mathrm{PCl}$ group $(0.011 \%)$ (Figure 1$)$. Technical aspects of the procedure, such as the choice of access site (femoral or radial sheath), catheter size, as well as guidewires, type of thrombectomies, and other devices, were at the operator's discretion. Patients were qualified for percutaneous revascularization and treated according to the current European Guidelines [12]. Antiplatelet therapy was im- plemented according to the current European Guidelines [13]. Periprocedural stroke was diagnosed according to the current recommendations [14]. The protocol complied with the 1964 Declaration of Helsinki, and all participants provided their written informed consent for the percutaneous intervention. Due to the retrospective nature as well as anonymization of the collected data and registry, obtaining the consent of the Bioethics Committee was not required.

\section{Endpoints}

The primary endpoint of the current study was to assess the frequency of periprocedural strokes in patients undergoing percutaneous coronary diagnostics and/or intervention and its possible fluctuation through the 6-year-long period. The secondary endpoint was to assess the predictors of periprocedural stroke in the group of patients undergoing DCA and $\mathrm{PCI} \pm \mathrm{DCA}$.

\section{Statistical analysis}

Categorical variables are presented as numbers and percentages. Continuous variables are expressed as mean (standard deviation). Normality was assessed via the Shapiro-Wilk test. Equality of variance was evaluated using Levene's test. Differences between the 2 groups were compared using the Student's or Welch's t-test, depending on the equality of variances for normally distributed variables. The Mann-Whitney U test was applied for non-normally distributed continuous variables. Categorical variables were compared with Pearson's chi-squared or Fisher's exact test if $20 \%$ of the cells had an expected count of less than 5 (Monte Carlo simulation for Fisher's test using tables of higher dimensions than $2 \times 2$ ). All baseline/demographic characteristics were used as potential predictors of stroke in univariable logistic regression models. Then variables with $P$-value $<0.2$ or variables of clinical importance were included in the multivariable model. Final multivariable logistic regression models were constructed using minimization of Akaike Information Criterion to find predictors of stroke in the DCA and $\mathrm{PCI} \pm \mathrm{DCA}$ group. Statistical analysis was performed using the $\mathrm{R}$, version 3.5.3 (R Foundation for Statistical Computing 2019, Vienna, Austria) with the'Ime4', version 1.1-21 package. 


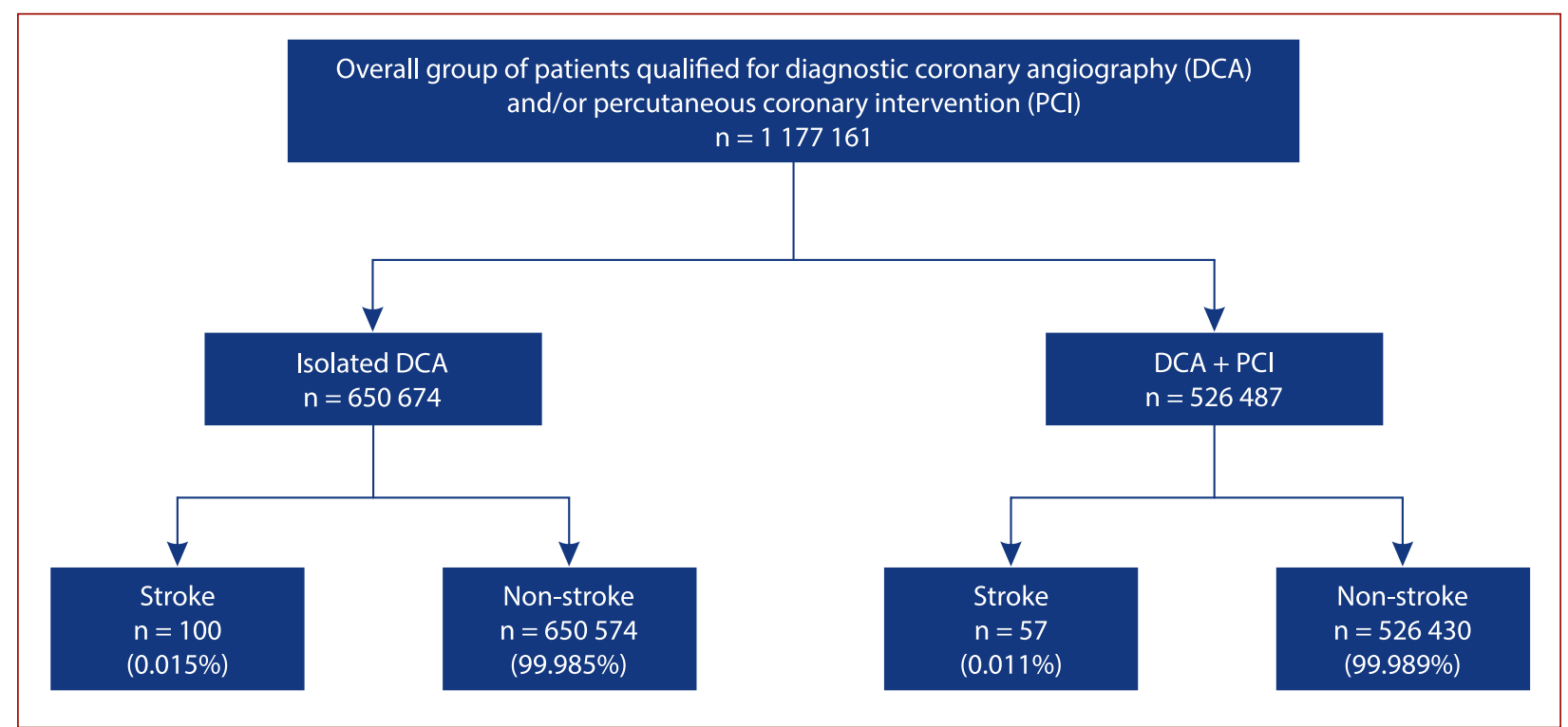

Figure 1. Patient flow chart

Table 1. Baseline patient characteristics and clinical presentation according to type of performed coronary procedure

\begin{tabular}{|c|c|c|c|c|c|c|}
\hline \multirow[t]{2}{*}{ Years } & \multicolumn{3}{|c|}{ Isolated diagnostic coronary angiography } & \multicolumn{3}{|c|}{$\mathrm{PCl} \pm$ coronary angiography } \\
\hline & $\begin{array}{l}\text { Stroke } \\
n=100\end{array}$ & $\begin{array}{l}\text { Non-stroke } \\
n=650574\end{array}$ & $\begin{array}{c}\text { Total } \\
n=650674\end{array}$ & $\begin{array}{l}\text { Stroke } \\
n=57\end{array}$ & $\begin{array}{l}\text { Non-stroke } \\
n=526430\end{array}$ & $\begin{array}{c}\text { Total } \\
n=\mathbf{5 2 6 4 8 7}\end{array}$ \\
\hline 2014 & $20(0.017)$ & $114129(99.983)$ & $114149(100)$ & $18(0.019)$ & 92597 (99.981) & $92615(100)$ \\
\hline 2015 & $16(0.014)$ & 110771 (99.986) & $110787(100)$ & $13(0.014)$ & 92774 (99.987) & $92787(100)$ \\
\hline 2016 & $12(0.01)$ & 113055 (99.99) & $113067(100)$ & $9(0.009)$ & 94425 (99.991) & $94434(100)$ \\
\hline 2017 & $17(0.015)$ & 110908 (99.985) & $110925(100)$ & $6(0.007)$ & 89624 (99.993) & $89630(100)$ \\
\hline 2018 & $18(0.017)$ & $104553(99.983)$ & $104571(100)$ & $7(0.009)$ & 81131 (99.991) & $81138(100)$ \\
\hline 2019 & $17(0.017)$ & $97158(99.983)$ & $97175(100)$ & $4(0.005)$ & 75879 (99.995) & $75883(100)$ \\
\hline$P$-value & 0.35 & - & - & 0.001 & - & - \\
\hline
\end{tabular}

Abbreviations: $\mathrm{PCl}$, percutaneous coronary intervention

\section{RESULTS}

\section{Frequency and trends of periprocedural stroke}

The frequency of periprocedural stroke assessed in the groups of patients is presented in Figure 1. While trends in the frequency of periprocedural stroke did not change significantly in the group undergoing DCA alone $(P=0.35)$, it decreased significantly in the $\mathrm{PCl} \pm \mathrm{DCA}$ group $(P=0.001)$ (Table 1).

\section{General characteristics}

Patients from the DCA group and with periprocedural stroke were significantly older when compared to the nonstroke sub-group (72.6 [8.7] vs. 66.3 [10.7] years; $P<0.001$ ). There were no significant differences in age between stroke and non-stroke patients from the DCA and $\mathrm{PCl} \pm \mathrm{DCA}$ groups (69.5 [13.1] vs. 67.1 [10.9] years; $P=0.1$ ). Considering sex differences, there were significantly more females in the stroke sub-group compared to non-stroke patients from the DCA and $\mathrm{PCl}$ groups (67.5\% vs. 52\%; $\mathrm{P}=0.02)$. This and other indices are presented in the Supplementary material, Table S1.

\section{Clinical presentation}

There were no significant differences in the clinical state before percutaneous intervention between the sub-group of stroke and non-stroke patients in the isolated DCA and $\mathrm{PCl} \pm \mathrm{DCA}$ groups of patients, as assessed by Killip-Kimball class grade (Supplementary material, Table S1). When considering the clinical presentation of coronary artery disease in the DCA group, significantly more patients in the stroke subgroup presented with acute myocardial infarction (AMI) at baseline (non-ST segment elevation myocardial infarction [NSTEMI] and ST-segment elevation myocardial infarction [STEMI]), while fewer patients presented with chronic coronary syndrome when compared to the nonstroke subgroup (Supplementary material, Table S1).

\section{Procedural indices}

Statistically, significantly more patients with periprocedural stroke were treated from femoral access when compared to radial (left and right radial) in the DCA alone and $\mathrm{PCI} \pm \mathrm{DCA}$ group (Supplementary material, Table S2). The patients from the DCA-alone group and with a periprocedural stroke presented significantly more with significant coro- 
nary atherosclerosis compared to the non-stroke patients (Supplementary material, Table S2). There were no such significant differences in the group of patients undergoing $\mathrm{PCl} \pm$ DCA (Supplementary material, Table S2).

\section{Periprocedural pharmacotherapy}

Acetyl-salicylic acid (ASA), unfractionated heparin, and $\mathrm{P} 2 \mathrm{Y}_{12}$ inhibitors were significantly more frequently used in the patients with periprocedural stroke when compared to the patients without stroke in the DCA-alone group, while this significance was maintained only for ASA in the $\mathrm{PCl} \pm$ DCA group (Supplementary material, Table S1). This and other pharmacotherapy treatments are presented in the Supplementary material, Table S1.

\section{Periprocedural complications and others}

Considering the periprocedural occurrence of cardiac arrests, there were no significant differences between the patients with or without periprocedural stroke in the DCA alone and $\mathrm{PCI} \pm \mathrm{DCA}$ groups (Supplementary material, Table S1). However, direct transport took place significantly more often in the case of patients with periprocedural stroke when compared to the non-stroke group in the DCA alone and $\mathrm{PCl} \pm \mathrm{DCA}$ groups (Supplementary material, Table S1).

\section{Predictors of stroke in patients undergoing DCA alone assessed by multivariable logistic regression analysis}

Among the independent predictors of periprocedural stroke occurrence in patients undergoing DCA, we con- firmed, via multivariable logistic regression analysis, prior stroke $(P<0.001)$, intravascular ultrasound during angiography $(P=0.03)$, optical coherence tomography performed during angiography $(P=0.03)$, greater contrast dose used during angiography $(P=0.007)$, femoral compared to radial access $(P=0.002)$, unfractionated heparin used during angiography $(P=0.01)$, direct transport to the catheterization laboratory $(P=0.04)$, older age $(P<0.001)$, left main coronary artery disease when compared to single-vessel disease $(P<0.001)$, and presence of multi-vessel disease in coronary angiography when compared to single-vessel disease $(P<0.001)$ (Figure 2 ).

\section{Predictors of stroke in patients undergoing $\mathrm{PCl} \pm \mathrm{DCA}$ assessed by multivariable logistic regression analysis}

When considering $\mathrm{PCI} \pm \mathrm{DCA}$ among the predictors of periprocedural stroke, we confirmed, by multivariable logistic regression analysis, prior stroke $(P<0.001)$, thrombolysis $(P=0.003)$, treatment with bivalirudin $(P<0.001)$, and ASA loading during $\mathrm{PCl}(P=0.003)$ (Figure 3$)$.

\section{DISCUSSION}

In summary, first of all, we confirmed that in the analyzed registry between the years 2014 and 2019, the incidence of periprocedural stroke did not change in the patients undergoing DCA, while it decreased significantly in the patients treated with $\mathrm{PCI} \pm \mathrm{DCA}$. Secondly, among the non-modifiable and confirmed predictors of periprocedural stroke (prior stroke, age, more advanced and disseminat-

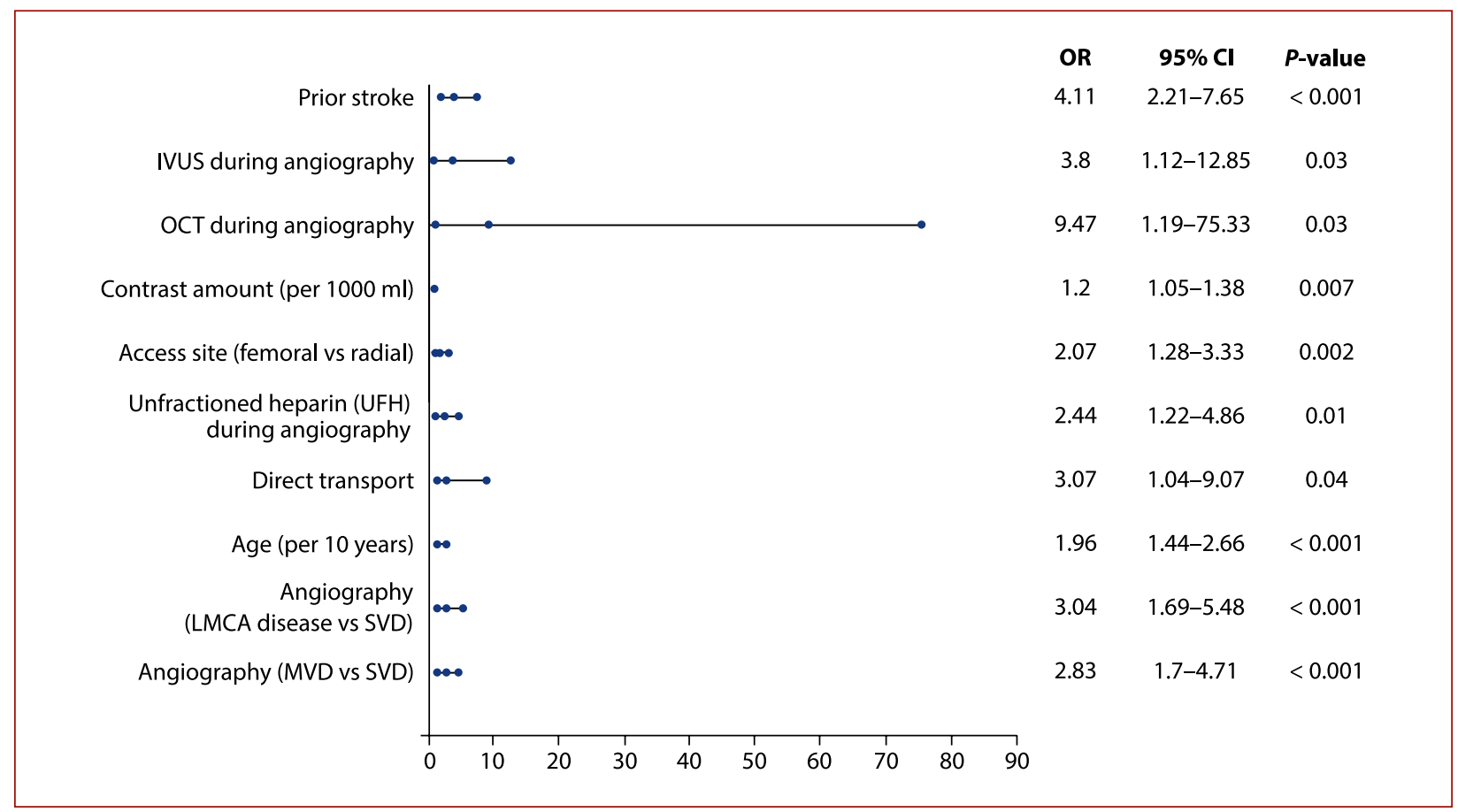

Figure 2. Predictors of periprocedural stroke in patients undergoing diagnostic coronary angiography assessed by multivariable logistic regression analysis

Abbreviations: CVD, cardiovascular disease; IVUS, intravascular ultrasound; LMCA, left main coronary artery atresia; MVD, multivessel coronary disease; OCT, optical coherence tomography; SVD, single vessel disease 


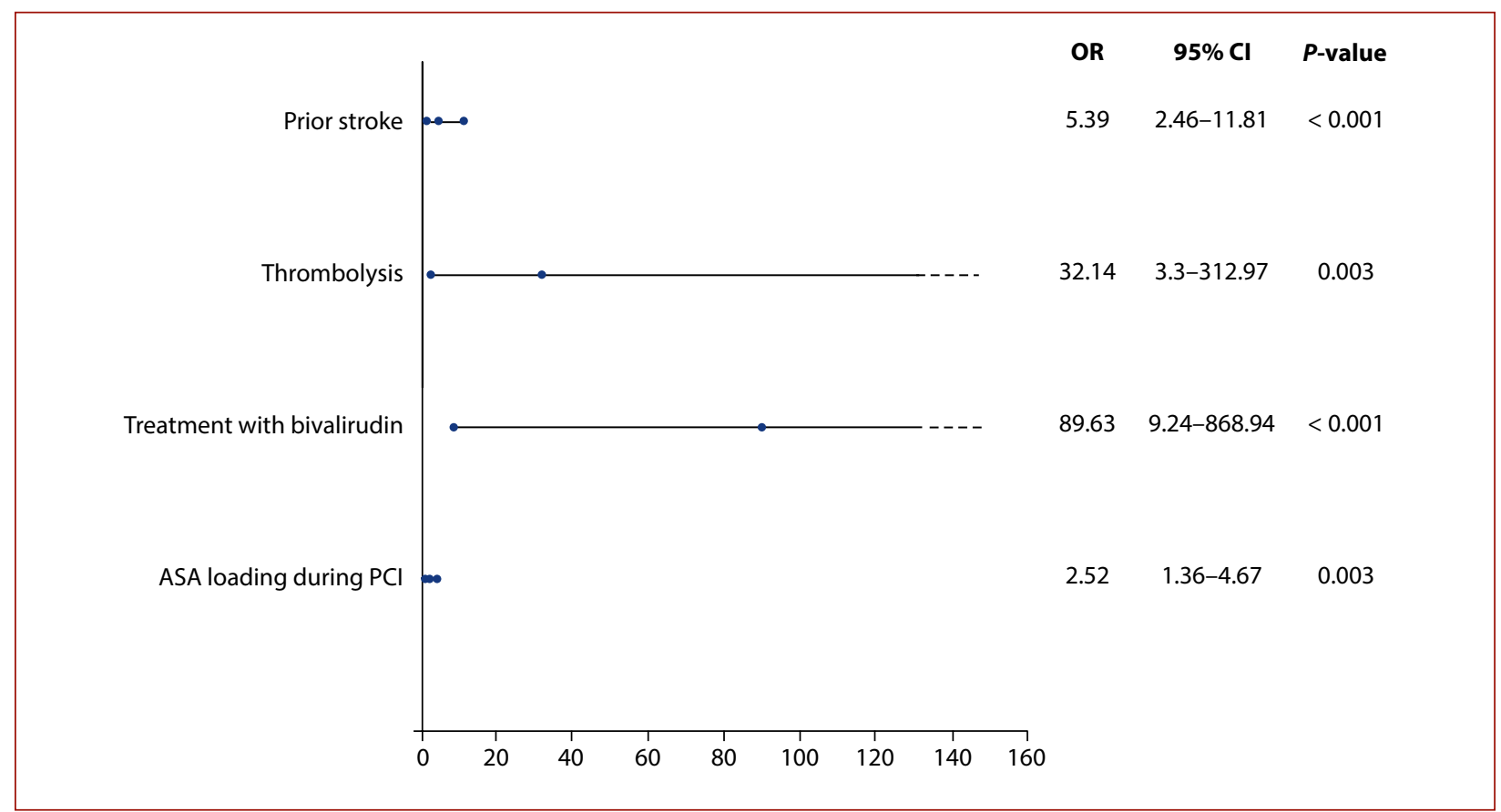

Figure 3. Predictors of periprocedural stroke in patients undergoing percutaneous coronary intervention \pm coronary angiography assessed by multivariable logistic regression analysis

Abbreviations: ASA, acetyl-salicylic acid; other — see Table 1

ed coronary atherosclerosis with the left main coronary artery atresia (LMCA) involvement, femoral access, and contrast amount) in the patients undergoing DCA, we also distinguished intravascular ultrasound (IVUS) and optical coherence tomography (OCT) use during DCA, as well unfractionated heparin use during DCA, and direct transport to the catheterization laboratory. Thirdly, we also identified predictors of periprocedural stroke in the patients treated with $\mathrm{PCI} \pm \mathrm{DCA}$, which included, among others, such well-recognized predictors as thrombolysis and prior stroke, treatment with bivalirudin, and ASA loading during $\mathrm{PCl}$.

The frequency of reported periprocedural stroke in patients undergoing DCA and $\mathrm{PCl}$ depends on several factors, which include, inter alia, the type of study (registry or prospective clinical trial), the duration of observed periprocedural period (periprocedural, in-hospital, or even post-discharge period), and the manner of stroke confirmation (computed tomography, cardiac magnetic resonance [CMR], or clinical symptoms). It may be concluded that in some circumstances, the incidence of periprocedural stroke is lower because the patients were observed only for a short-term period in the catheterization laboratory or when there was no diagnosis in the direction of the silent stroke (CMR). Therefore, in previously published studies, the rate of cerebrovascular disease complications after DCA and $\mathrm{PCl}$ was reported to be $0.1 \%-1 \%$ for DCA and $0.1 \%-0.6 \%$ for $\mathrm{PCl}$, which remains in line with our results [15]. The frequency of strokes related to DCA and $\mathrm{PCl}$ was usually lower in papers based on registries [16]. Nonetheless, the frequency of asymptomatic procedure-re- lated strokes could be even higher than 10\% [17]. In the majority of recently published studies, a stable frequency of periprocedural strokes related to DCA and $\mathrm{PCI}$ has been reported; however, in some studies, it was noted that there is an increasing trend in the overall group of patients treated with $\mathrm{PCl}$ [5]. The authors concluded that this is owing to the increasing complexity of $\mathrm{PCl}$ over time (radial access, chronic total occlusions, use of mechanical circulatory support devices, or multivessel disease with higher atherosclerotic plaque burden) [5].

Identifying predictors of stroke related to DCA and $\mathrm{PCl}$ could help to develop effective prevention strategies, especially against modifiable predictors. Older age, female sex, vascular disease, renal failure, prior stroke, or transient ischemic attack, heart failure, use of mechanical circulatory devices, or vein graft interventions were reported among predictors of stroke [16]. In the current study, we divided predictors of stroke into two groups: those related to DCA and those related to $\mathrm{PCl} \pm \mathrm{DCA}$.

\section{Predictors of stroke related to DCA}

Prior stroke is a common, usually strong, and sanctioned finding as a predictor of stroke related to DCA and $\mathrm{PCl} \pm \mathrm{DCA}$ [15]. Intravascular ultrasound is often used in patients treated due to advanced atherosclerosis that is frequently located in the aorto-ostial area, which could, in some cases, predispose to embolization by small debris released during $\mathrm{PCl}$. Additionally, IVUS is recommended for the assessment of possible embolic etiology of AMI in patients with non-obstructive coronary arteries. These maneuvers with the IVUS probe could, in some circum- 
stances, be related to thrombus dislodgement and further cerebrovascular embolization [18]. In recently published studies, it has been reported that the currently used non-occlusive technique of optical coherence tomography improves its feasibility and reduces the complication risk [19]. The complication risk based on smaller studies varies between $0 \%-2 \%$, but on a large-scale registry by van der Sijde et al. [19], it was demonstrated that complications occur there rarely $(<0.2 \%)$. However, major complications during OCT occur, including coronary spasm, vessel dissection, thrombus, and ventricular fibrillation, and some of them may lead to cerebrovascular adverse events [20]. Greater contrast amount used during DCA and $\mathrm{PCI} \pm$ DCA is usually related to more complicated procedures, more advanced and disseminated atherosclerosis, more severe state, lower left ventricular ejection fraction, or use of left ventricular support mechanical devices, which are strictly related to the increased probability of thrombus formation and the risk of procedure-related stroke [7].

Shoji et al. [21] demonstrated that consecutive patients undergoing $\mathrm{PCl}$ from transradial access were at a reduced risk of periprocedural stroke compared to transfemoral intervention. Jurga et al. [22] revealed that radial access used for DCA generates more particulate cerebral microemboli than femoral access and thus, it may influence the occurrence of silent cerebral injury. They also suggested that manipulation in the subclavian artery may cause silent cerebral microemboli; otherwise, clinically relevant cerebral infarction may originate from large plaques, mainly located in the aortic arch [22]. Khatibzadeh et al. [23] demonstrated that localization of atherosclerotic plaques prone to dislodgement in the thoracic aorta (descending and arch) predispose to ischemic stroke in patients treated from femoral access.

Using heparin during angiography may lead to heparin-induced thrombocytopenia syndrome (HITS) in a short period, especially among patients in a serious condition with a prevalence of additional risk factors. HITS is an uncommon immune disorder mediated by antibodies to the heparin-platelet factor 4 complex [24]. It can cause new or worsening of previously present blood clots, which can even result in a periprocedural stroke. The occurrence of immune thrombocytopenia may be treated as an independent risk factor of ischemic stroke [25]. In the case of direct transport, patients treated in an emergency mode are associated with a greater rate of periprocedural strokes. It has been reported that periprocedural stroke occurs more often in patients treated with $\mathrm{PCl}$ due to $\mathrm{AMI}(0.8 \%-1.4 \%)$ than those treated for unstable angina $(0.4 \%-10.8 \%)$ [9, 26]. This was also confirmed in the study published by Budaj et. al. [27], in which the frequency of stroke was $1.3 \%$ in STEMI, $0.9 \%$ in NSTEMI, and $0.5 \%$ in unstable angina patients. In another study published by Werner et al. [15], it was confirmed that hemodynamic instability, which is strictly related to direct transport, was among predictors of stroke related to $\mathrm{PCl}$.
It has been found that not only older age, type of plaque, and its location in the aorta (ascending, descending, and arch) are related to a greater amount of debris that can be scraped from the artery wall, but it has also been confirmed that the catheter type plays an important role. Among those more prone to scrape debris from the internal wall of the aorta, Keeley et al. [28] found Judkins left, multipurpose, and voda left. Tokushige et al. [8] demonstrated that asymptomatic strokes detected by CMR within 48 hours after DCA could even reach up to $20 \%$ in older patients, following coronary artery by-pass grafting (CABG). In most publications, older age was present among the predictors of $\mathrm{PCl}$-related stroke; however, in our study, this was confirmed only for isolated DCA [15]. In several previously published studies, a relationship between $\mathrm{PCI}$ in patients with triple vessel disease and procedure-related stroke has been verified [4].

\section{Predictors of stroke related to $P C I \pm D C A$}

In various publications, prior stroke (as well as female sex, atrial fibrillation, heart failure, diabetes mellitus, chronic renal failure atherosclerotic cardiovascular disease, left ventricular thrombus, hypercoagulable state, and CABG during admission) was confirmed as a predictor of periprocedural stroke in patients treated with $\mathrm{PCl}$ due to AMI [10].

Most of the strokes related to DCA and $\mathrm{PCl}$ are supposed to be of embolic etiology, from either dislodgement of a clot or atheromatous debris from the aortic arch or thrombus formation on the guide catheter [29]. However, in the case of thrombolysis, it seems that the root cause is partial fragmentation of coronary artery thrombus and its dislodgement to the aorta during any manipulation in the ostium of the target coronary artery.

The use of eptifibatide and bivalirudin was found to be non-protective in patients undergoing cardiac catheterization in terms of the frequency of periprocedural stroke [4]. The authors explained these results by the dominance of the non-thrombotic mechanism of embolus etiology [4]. Our analysis even allowed us to demonstrate that bivalirudin was significantly correlated with the greater rate of intraprocedural strokes. Nowadays, bivalirudin is used in patients with $\mathrm{AMI}$, and this could be the key factor that determines this relationship.

Acute antiplatelet (ASA and $\mathrm{P} 2 \mathrm{Y}_{12}$ receptor inhibitors) therapy was found to be an independent predictor of ischemic stroke related to $\mathrm{PCl}$ due to $\mathrm{AMI}$, which was also confirmed in our analysis [30]. Hachet et al. demonstrated that relationship for patients with $\mathrm{AMI}$ treated via $\mathrm{PCl}$, whereas a relationship that was found in our patients undergoing CLA, included also patients with non-obstructive AMI. It could be also hypothesized that preprocedural treatment with ASA could decrease a potential risk of procedure-related stroke in patients undergoing percutaneous coronary catheterization.

In previously published studies, it has been reported that prior $C A B G$ was found to be independently related to 
periprocedural stroke in patients undergoing DCA. However, in our study, this factor was not confirmed by multivariable logistic regression analysis [8]. In another study published by Kawamura et al. [31], it was demonstrated by multivariable logistic regression analysis that left ventricular ejection fraction was the only independent predictor for stroke in patients treated with $\mathrm{PCl}$ due to acute myocardial infarction. We were not able to assess this relationship because our dataset did not include this parameter.

\section{Limitations}

Periprocedural complications, including stroke, depend on self-initiated reporting by the operator, under-reporting cannot be excluded. The diagnosis of stroke was predominantly based on clinical symptoms, made by the treating interventional cardiologist. We did not have information on the type of catheters and their diameter. Furthermore, the data on left ventricular ejection fraction, the frequency of atrial fibrillation, or details on potential complications were unavailable. The ORPKI registry does not allow to count all procedure-related strokes which occur during hospitalization after leaving the catheterization laboratory, nor were the outcomes of patients beyond hospital discharge available. All the data gathered in the ORPKI registry referred to the stay in the catheterization laboratory. A typical feature of a large national registry is dataset completeness, which undoubtedly, could cause certain bias in the statistical calculation, apart from a wide range of statistical possibilities to decrease this influence.

\section{CONCLUSIONS}

Based on the large national registry, the incidence of periprocedural stroke did not change in the patients undergoing DCA, while it decreased significantly in the patients treated with DCA and/or PCl. Among the non-modifiable and confirmed predictors of periprocedural stroke in patients undergoing DCA (prior stroke, age, more advanced and disseminated coronary atherosclerosis with the LMCA involvement femoral access, and contrast amount), we also distinguished IVUS and OCT use during DCA, as well unfractionated heparin use during DCA, and direct transport to the catheterization laboratory. There were fewer predictors of periprocedural stroke in patients treated with DCA and/or PCl, which included, among others, such well-recognized predictors as thrombolysis and prior stroke, treatment with bivalirudin, and ASA loading during $\mathrm{PCl}$.

\section{Supplementary material}

supplementary material is available at https://journals. viamedica.pl/kardiologia_polska.

\section{Article information}

Conflict of interest: None declared.

Open access: This article is available in open access under Creative Common Attribution-Non-Commercial-No Derivatives 4.0 Interna- tional (CC BY-NC-ND 4.0) license, allowing to download articles and share them with others as long as they credit the authors and the publisher, but without permission to change them in any way or use them commercially. For commercial use, please contact the journal office at kardiologiapolska@ptkardio.pl.

How to cite: Staszczak B, Malinowski KP, Wańha W, et al. Frequency and predictors of diagnostic coronary angiography and percutaneous coronary intervention related to stroke. Kardiol Pol. 2021; 79(10): 1099-1106, doi: 10.33963/KP.a2021.0100.

\section{References}

1. Dukkipati $\mathrm{S}, \mathrm{O}^{\prime} \mathrm{Neill}$ WW, Harjai KJ, et al. Characteristics of cerebrovascular accidents after percutaneous coronary interventions. J Am Coll Cardiol. 2004; 43(7): 1161-1167, doi: 10.1016/j.jacc.2003.11.033, indexed in Pubmed: 15063423.

2. Fuchs S, Stabile E, Kinnaird TD, et al. Stroke complicating percutaneous coronary interventions: incidence, predictors, and prognostic implications. Circulation. 2002; 106(1): 86-91, doi: 10.1161/01. cir.0000020678.16325.e0, indexed in Pubmed: 12093775.

3. Tokarek T, Dykla D, Popiela T, et al. Immediate mechanical thrombectomy with DynaCT evaluation after percutaneous coronary intervention complicated with acute ischemic stroke. Kardiol Pol. 2021; 79(9): 1038-1039, doi: 10.33963/KP.a2021.0043, indexed in Pubmed: 34166519.

4. Korn-Lubetzki I, Farkash R, Pachino RM, et al. Incidence and risk factors of cerebrovascular events following cardiac catheterization. J Am Heart Assoc. 2013; 2(6): e000413, doi: 10.1161/JAHA.113.000413, indexed in Pubmed: 24231658.

5. Alkhouli M, Alqahtani F, Tarabishy A, et al. Incidence, predictors, and outcomes of acute ischemic stroke following percutaneous coronary intervention. JACC Cardiovasc Interv. 2019; 12(15): 1497-1506, doi: 10.1016/j.jcin.2019.04.015, indexed in Pubmed: 31395220.

6. Goel K, Gupta T, Gulati R, et al. Temporal trends and outcomes of percutaneous coronary interventions in Nonagenarians: a national perspective. JACC Cardiovasc Interv. 2018; 11(18): 1872-1882, doi: 10.1016/j. jcin.2018.06.026, indexed in Pubmed: 30236360.

7. Hoffman SJ, Routledge HC, Lennon RJ, et al. Procedural factors associated with percutaneous coronary intervention-related ischemic stroke. JACC Cardiovasc Interv. 2012; 5(2): 200-206, doi: 10.1016/j.jcin.2011.10.014, indexed in Pubmed: 22361605.

8. Tokushige A, Miyata M, Sonoda T, et al. Prospective study on the incidence of cerebrovascular disease after coronary angiography. J Atheroscler Thromb. 2018; 25(3): 224-232, doi: 10.5551/jat.41012, indexed in Pubmed: 28855432.

9. Valgimigli M, Frigoli E, Leonardi S, et al. Radial versus femoral access in patients with acute coronary syndromes undergoing invasive management: a randomised multicentre trial. Lancet. 2015;385(9986): 2465-2476, doi: 10.1016/S0140-6736(15)60292-6, indexed in Pubmed: 25791214.

10. Albaeni A, Harris $\mathrm{CM}$, Nasser $\mathrm{H}$, et al. In-Hospital acute ischemic stroke following ST-elevation myocardial infarction. Int J Cardiol Heart Vasc. 2020; 31: 100684, doi: 10.1016/j.jicha.2020.100684, indexed in Pubmed: 33344755.

11. Januszek R, Siudak Z, Malinowski KP, et al. Aspiration thrombectomy in patients with acute myocardial infarction-5-year analysis based on a large national registry (ORPKI). JClin Med. 2020; 9(11), doi: 10.3390/jcm9113610, indexed in Pubmed: 33182436.

12. Sousa-Uva M, Neumann FJ, Ahlsson A, et al. 2018 ESC/EACTS Guidelines on myocardial revascularization. Eur Heart J. 2019; 40(2): 87-165, doi: 10.1093/eurheartj/ehy394, indexed in Pubmed: 30165437.

13. Editorial A. 2017 ESC focused update on dual antiplatelet therapy in coronary artery disease developed in collaboration with eacts. Russ J Cardiol. 2018(8): 113-163, doi: 10.15829/1560-4071-2018-8-113-163.

14. Powers WJ, Rabinstein AA, Ackerson T, et al. Guidelines for the Early Management of Patients With Acute Ischemic : 2019 Update to the 2018 Guidelines for the Early Management of Acute Ischemic : A Guideline for Healthcare Professionals From the American Heart Association/American Association. Stroke. 2019; 50: e344-e418, doi: 10.1161/STR.0000000000000211.

15. Werner $N$, Bauer $T$, Hochadel $M$, et al. Incidence and clinical impact of stroke complicating percutaneous coronary intervention: results of the 
Euro heart survey percutaneous coronary interventions registry. Circ Cardiovasc Interv. 2013; 6(4): 362-369, doi: 10.1161/CIRCINTERVENTIONS.112.000170, indexed in Pubmed: 23899872.

16. Aggarwal A, Dai D, Rumsfeld JS, et al. American College of Cardiology National Cardiovascular Data Registry. Incidence and predictors of stroke associated with percutaneous coronary intervention. Am J Cardiol. 2009; 104(3):349-353, doi: 10.1016/j.amjcard.2009.03.046, indexed in Pubmed: 19616666.

17. Kim IC, Hur SH, Park NH, et al. Incidence and predictors of silent embolic cerebral infarction following diagnostic coronary angiography. Int J Cardiol. 2011;148(2): 179-182, doi: 10.1016/j.jjcard.2009.10.053, indexed in Pubmed: 19942304.

18. Hausmann D, Erbel R, Alibelli-Chemarin MJ, et al. The safety of intracoronary ultrasound. A multicenter survey of 2207 examinations. Circulation. 1995; 91(3):623-630, doi: 10.1161/01.cir.91.3.623, indexed in Pubmed: 7828285.

19. van der Sijde JN, Karanasos A, van Ditzhuijzen NS, et al. Safety of optical coherence tomography in daily practice: a comparison with intravascular ultrasound. Eur Heart J Cardiovasc Imaging. 2017; 18(4): 467-474, doi: 10.1093/ehjci/jew037, indexed in Pubmed: 26992420.

20. Barlis P, Gonzalo N, Di Mario C, et al. A multicentre evaluation of the safety of intracoronary optical coherence tomography. Eurolntervention. 2009; 5(1): 90-95, doi: 10.4244/eijv5i1a14, indexed in Pubmed: 19577988.

21. Shoji S, Kohsaka S, Kumamaru H, et al. Stroke after percutaneous coronary intervention in the era of transradial intervention. Circ Cardiovasc Interv. 2018; 11(12): e006761, doi: 10.1161/CIRCINTERVENTIONS.118.006761, indexed in Pubmed: 30545258.

22. Jurga J, Nyman J, Tornvall P, et al. Cerebral microembolism during coronary angiography: a randomized comparison between femoral and radial arterial access. Stroke. 2011; 42(5): 1475-1477, doi: 10.1161/STROKEAHA.110.608638, indexed in Pubmed: 21393589.

23. Khatibzadeh $M$, Mitusch $R$, Stierle $U$, et al. Aortic atherosclerotic plaques as a source of systemic embolism. J Am Coll Cardiol. 1996; 27(3):664-669, doi: 10.1016/0735-1097(95)00526-9, indexed in Pubmed: 8606279.
24. Gupta S, Tiruvoipati R, Green C, et al. Heparin induced thrombocytopenia in critically ill: Diagnostic dilemmas and management conundrums. World JCrit Care Med.2015;4(3):202-212, doi: 10.5492/wjccm.v4.i3.202, indexed in Pubmed: 26261772.

25. Park HK, Lee SH. Ischemic stroke associated with immune thrombocytopenia: lesion patterns and characteristics. Neurol Sci. 2014; 35(11): 1801-1806, doi: 10.1007/s10072-014-1843-0, indexed in Pubmed: 24880747.

26. Mojadidi MK, Kumar P, Mahmoud AN, et al. Complete or culprit-only revascularization for patients with multivessel coronary artery disease undergoing percutaneous coronary intervention: a pairwise and network meta-analysis of randomized trials. JACC Cardiovasc Interv. 2017; 10(4): 315-324, doi: 10.1016/j.jcin.2016.11.047, indexed in Pubmed: 28231899.

27. Budaj A, Flasinska K, Gore JM, et al. Magnitude of and risk factors for in-hospital and postdischarge stroke in patients with acute coronary syndromes: findings from a Global Registry of Acute Coronary Events. Circulation. 2005; 111(24): 3242-3247, doi: 10.1161/CIRCULATIONAHA.104.512806, indexed in Pubmed: 15956123.

28. Keeley EC, Grines CL. Scraping of aortic debris by coronary guiding catheters: a prospective evaluation of 1,000 cases. J Am Coll Cardiol. 1998; 32(7): 1861-1865, doi: 10.1016/s0735-1097(98)00497-5, indexed in Pubmed: 9857864.

29. Khatri $P$, Kasner SE. Ischemic strokes after cardiac catheterization: opportune thrombolysis candidates? Arch Neurol. 2006; 63(6): 817-821, doi: 10.1001/archneur.63.6.817, indexed in Pubmed: 16769862

30. Hachet O, Guenancia C, Stamboul K, et al. Frequency and predictors of stroke after acute myocardial infarction: specific aspects of in-hospital and postdischarge events. Stroke. 2014; 45(12): 3514-3520, doi: 10.1161/STROKEAHA.114.006707, indexed in Pubmed: 25370585.

31. Kawamura A, Lombardi DA, Tilem ME, et al. Stroke complicating percutaneous coronary intervention in patients with acute myocardial infarction. Circ J. 2007; 71(9): 1370-1375, doi: 10.1253/circj.71.1370, indexed in Pubmed: 17721013. 